\title{
Why corporate power is a public health priority
}

The marketing campaigns of multinational corporations are harming our physical, mental, and collective wellbeing. Gerard Hastings urges the public health movement to take action

\author{
Gerard Hastings director \\ Institute for Social Marketing, University of Stirling and the Open University, Stirling FK9 4LA, UK
}

The work of Professor Richard Doll provides two key lessons for public health. The first, that we must do all we can to eradicate the use of tobacco, has been well learnt and is being energetically acted upon. The second, more subtle learning - that our economic system has deep flaws - remains largely ignored. And yet, lethal though tobacco is, the harm being done to public health by our economic system is far greater.

\section{Industrial epidemics}

Furthermore, the two are intimately connected: tobacco has remained such an intractable problem only because our economic system allows free ranging corporations to market it. The same applies to the other two "industrial epidemics" that constitute such a large share of the public health burden: alcohol misuse and obesity. In each case evocative promotion, ubiquitous distribution, perpetual new product development, and seductive pricing strategies are used to encourage unhealthy consumption. And in each case painstaking research and review have shown the obvious truth that this marketing effort succeeds, especially with the young. ${ }^{2-4}$ The consequence has been the inevitable escalation of lifestyle illnesses such as cancer, heart disease, cirrhosis, and diabetes.

However, the impact of marketing on public health goes much deeper than this. Marketing textbooks lionise the consumer: our complete satisfaction is the essence of successful business (provided we can afford to pay). The result is an unstinting hunt for new needs and wants (or, increasingly, whims) to satisfy, and a population that has a burgeoning sense of entitlement. The damaging effect of this favouritism is shown in the pharmaceutical business, which pays more attention to the trivial complaints of the rich than the life threatening sicknesses of the poor. As Bakan points out, "Of the 1400 new drugs developed between 1975 and 1999, only 13 were designed to treat or prevent tropical diseases and three to treat tuberculosis. In the year 2000, no drugs were being developed to treat tuberculosis, compared to eight for impotence or erectile dysfunction and 7 for baldness." 5 This dangerously indulgent focus starts at birth, because children offer the corporate marketer a lifetime of profitability (box 1)
Sadly, as any philosopher or theologian would predict, such pampering does not bring happiness. Once basic needs are satisfied, the correlation between material possessions and contentment rapidly dissipates. But marketing keeps us craving more: the paradox of a system devoted to our satisfaction is that it depends on our perpetual dissatisfaction; after all once we are satisfied we stop shopping. In this way it undermines our mental as well as our physical wellbeing.

\section{The customer always comes second}

Furthermore, the corporate marketers' focus on customer satisfaction is in reality specious; the fiduciary duty of corporations gives them a legal obligation to prioritise the needs, not of the consumer, but of the shareholder. How else could we have tobacco companies, who are consummate marketers, continuing to produce products that kill one in two of their most loyal customers? The corporate marketers' self centred purpose, then, is "to recognise and achieve an economic advantage which endures." " Not an economic advantage for the customer-just for the company. This is the same single minded and dysfunctional principle that continues to drive the financial sector.

A key function of marketing is to mask these uncomfortable truths by disguising inanimate corporate monoliths as benign friends under the guise of branding. The role of branding in youth smoking ${ }^{8}$ and drinking ${ }^{9}$ has been well documented, and a recent study in California among 3-5 year olds showed that children's food preferences are being moulded by McDonald's branding even before they have learnt to tie their shoelaces. ${ }^{10}$ Items that came in McDonald's wrappers were thought to taste better, even if they were foods like carrots; on the other hand McDonald's products didn't taste as good without the liveried packaging. These effects were apparent across the group, but most marked among those who had been most exposed to McDonald's and its advertising. Marketers are clearly succeeding in their aim "to start building up their brand consciousness and loyalty as early as possible."

However, susceptibility to the "emotional benefits" of branding reaches way beyond toddlers and teens; it touches us all. The 


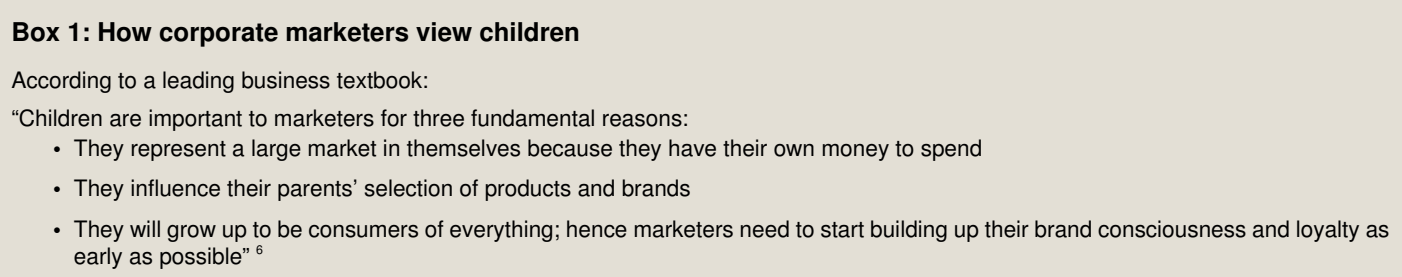

2005 Health Select Committee investigation into the pharmaceutical industry showed that it is even being used to influence general practitioners' prescribing practices (figure $\downarrow$ ). No wonder the committee's final report expressed “over-riding concerns about the volume, extent, and intensity of the industry's influence, not only on clinical medicine and research but also on patients, regulators, the media, civil servants, and politicians." 11

\section{Collective harm}

The harmful consequences of corporate marketing are even more apparent at a collective level. Marketers, as I noted above, are only interested in catering for the needs of those with money; as the business textbooks put it, target markets have to be accessible, responsive, and (above all) viable. The key concern is to reach people with persuasive marketing campaigns, and having done so, be confident that they will be both willing and able to make the purchase. So even as the "haves" get more, the "have nots" get less - and the resulting exacerbation of inequalities damages the health and wellbeing of both rich and poor. ${ }^{13}$ The distortions in the pharmaceutical market described above only serve to underline the systemic nature of the problem.

Not that disadvantaged groups completely escape the attentions of corporate marketers. Once the well-off are sated, or become disenchanted with product offerings, the disadvantaged get their turn in the sun. So now the beverage alcohol industry has got people in the developed world consuming as much booze as is humanly possible, it is turning its attention to developing countries. ${ }^{14}$ Similarly the social patterning of smoking in the UK has led tobacco companies to focus their efforts on poorer groups-hence the expansion in economy brands and price promotions. ${ }^{15}$

On a broader scale, marketers also recognise that context matters - that norms, mores, and, above all, laws have a big impact on our consumption behaviour. They therefore market to stakeholders and politicians in a bid to influence the policy agenda and thereby undermine what is public health's most important armamentarium. The alcohol industry's activities in the UK provide an instructive example. Corporate social responsibility efforts have included the funding of midwife training, support for non-governmental organisations in areas such as schools education, ${ }^{16}$ and addiction services, ${ }^{17}$ and the establishment of the Drinkaware Trust (set up to promote "the facts about alcohol"). All are carefully designed to position the industry as part of the solution rather than the problem. The subsequent decision by the UK government to implement its public health responsibility deal, which has made the alcohol industry (and other corporate interests) partners in the policy making process, shows that the strategy worked. It also points out the potential for public health harm, as an evidence base that has established the urgent need to reduce per capita consumption falls prey to the business model that demands growth.
Thinking more broadly still, the biggest effect that all this remorseless corporate marketing has on public health comes even further upstream - at a planetary level. We have built a system where continuous growth, fed by marketing driven excess consumption by the already well-off, is inevitably coming into conflict with the limits of a finite planet. This is now threatening public health far more seriously than the activities of any one industry - even one as egregious as tobacco- will ever do.

\section{Broadening public health}

These are massive problems that demand urgent attention and radical measures. There are some signs that public health is up for this challenge. The Framework Convention on Tobacco Control - "the world's first global public health treaty" 18 — shows that the global reach of corporate power can be controlled. Similarly, Marmot's pioneering work on the social determinants of health shows that there is an appetite for taking a broad perspective and "turning public health knowledge into political action." ${ }^{19}$ And, more recently, Rayner and Lang have called for a broader "ecological" perspective which recognises that "public health is often improved by movements and people prepared to challenge conventional assumptions and the status quo."20

However, Rayner and Lang also point out that "public health remains strangely marginal in public discourse as well as patchy in execution" 20 - and there are telling signs that we are failing to address this larger agenda. Our focus has become increasingly narrow and technocratic. We are, it seems, happier conducting randomised controlled trials of leaflet interventions or calculating algorithms that mean little outside the laboratory than challenging a system that is both deeply unfair and hopelessly unsustainable.

Public health workers have also become increasingly fragmented into disciplinary silos. Tobacco experts rarely speak to those in alcohol, nutrition, or sexual health, with no apparent recognition that, far from being unique and separate, the behaviours they all address comprise a typical Saturday night out for large sectors of the population. This also blinds us to the importance of individual empowerment. We beetle away at micromanaging specific behaviours and ignore the key message emerging from the public health evidence base - that for the first time in human history we now know how we can take a measure of control over our own health and longevity. By the same token we barely acknowledge the harm being done by our economic system, which undermines our critical faculties and sense of agency with perpetual messages of materialism and unwarranted entitlement. L'Oreal's corrosive slogan, "Because we are worth it," has become the leitmotiv of society on our watch.

It is little surprise, then, that corporate capitalism has gone from strength to strength and is taking over what should be core public health roles; we have got the responsibility deals we deserve. And our timorous protestations at this preferment of the fox to the keeper of the chicken coop can so easily be brushed aside because we have no public profile; we jettisoned that along with 
the Health Education Authority, when we failed to protect it from government closure.

Indeed, far from tackling and challenging the corporate marketers, we seem set on doing their bidding. We work with them on the Drinkaware Trust, in full knowledge that this makes us no more than junior executives in a textbook example of stakeholder marketing. The Health Select Committee, having warned us of the unwarranted influence of the pharmaceutical industry on our work, thinks it is necessary to stress the need "to examine critically the industry's impact on health to guard against excessive and damaging dependencies." But we lack the vision to do so, and even were we to regain it, have ceded our place at the top table. Our job is to keep quiet and clean up the mess made by the big boys; we have become janitors when the urgent need is for janissaries.

Moving beyond the topic specific, where is the public health contribution to such pressing problems as the corporate takeover of the Olympics - an event that should be a beacon of healthy activity not another shopping opportunity-or the debate about the coalition government abandoning its green agenda; or the financial crisis and corporate greed? Would a journalist even think about coming to public health for a comment on any of these?

As Rayner and Lang argue, public health needs a radical shake up; we have to revitalise-reinvent-our discipline. This reinvention has to recognise the increasingly unhealthy dominance of corporate marketing on our lives; Marmot's focus on the social determinants of ill health needs to be matched with an equal concern for the commercial determinants of ill health. As a contribution to this debate, I offer the following suggestions:

Independent public health body - We urgently need to re-establish a public health body in the UK that is linked to but clearly untrammelled by government-and completely insulated from vested interest. We have to start once again speaking unfettered truth to power. Through this we can also begin to rebuild a respected relationship with the public; now more than ever people need a champion to speak up for their real needs, rather than the phoney ones teased and tempted by corporate capitalism.

Wider vision-We have to lift our eyes above the quotidian: to remember that public health is not just about pump handles but also water resources. We can and should be offering a geopolitical vision with greater equality as its central pledge. This vision must consider the relationship between business and society. Multinational corporations will continue to be an important part of our economic system, if only because complex societies need the logistics and efficiencies they can deliver. It is difficult, for instance, to see how a city like London could continue to feed itself without supermarkets. However, public health has a legitimate and crucial role in asking questions about the extent of their power, the crassness of the fiduciary imperative, and the almost complete lack of responsibility being taken for externalities.

Rein in marketing - Unbridled marketing should also be energetically challenged. If, for example, the advertising of tobacco can be banned because smoking harms the individual, should not all advertising be much more circumscribed because the consumption it engenders harms the planet? Similarly, marketing is currently a right taken for granted; given its effect on inequalities should it not more properly be seen as a carefully controlled responsibility? Or again, what would be the pros and cons of requiring all corporations to show the effect that their marketing is having on health and welfare?
Challenge profit as a measure of success-More positively, we should question the legitimacy of marketing, which we know to be so powerful, being used simply to boost consumption and corporate profitability. Broader conceptions of success are needed that move beyond finance and focus instead on human welfare. Public health is perfectly equipped to lead this new enlightenment, starting with the WHO's multifaceted definition of health as "a state of complete physical, mental and social wellbeing and not merely the absence of disease or infirmity." Regain political leverage-We must demand a seat at the political top table, not just in health but in finance. Recent events in the banking sector confirm an age old lesson that fiscal policy has at least as much effect on morbidity and mortality as anything done in health ministries. Public health is too important to be left to economists and politicians, prey as they so obviously are to the cynical ministrations of the corporate marketer.

Think global-Finally, we have to recognise that our public health travails in the UK have global echoes and reverberations. Marketing campaigns have long since superseded mere national boundaries, $\mathrm{WHO}$ has been under well evidenced pressure from corporate interests for decades,${ }^{21}$ and the public health mistakes we have made in the UK will be visited ever more energetically on poorer countries. When we flirt with the corporates developing countries get ravished. Everything we do should respect this international agenda and related responsibilities.

\section{An ambitious pitch}

I accept this is an ambitious pitch. Public health has to demand a place at the macroeconomic table; it has to contribute to the debate about where corporate capitalism is going and ensure that the public health implications of business decision making are fully appreciated. The business sector is certainly not shy of putting forward its view of how the world should be organised for the greater good of business (see box 2 for example). If public health can develop a similar boldness of purpose we will be able to graduate from the post hoc reduction of specific harm, to a pre-emptive quest for an economic system that actively promotes better public health. We have to take the lead in a movement away from a world driven by abeyance to the corporate bottom line and the enrichment of an elite to one that prioritises physical, mental, social, and planetary wellbeing.

Contributors and sources: $\mathrm{GH}$ is the director of the CRUK Centre for Tobacco Control Research; a principal investigator on the International Tobacco Control Study, the UK Centre for Tobacco Control Studies, and the MRC funded APISE study; and a member of the Public Health Research Consortium. In these roles he has conducted research, advised national and international public bodies, and written articles and books on the impact of business on society. His latest book. The Marketing Matrix: How the Corporation Gets Its Power and How We Can Reclaim It, will be published by Routledge later this year.

Competing interests: The author has completed the ICMJE unified disclosure form at www.icmje.org/coi_disclosure.pdf (available on request from the corresponding author) and declares no support from any organisation for the submitted work; no financial relationships with any organisation that might have an interest in the submitted work in the previous three years; and no other relationships or activities that could appear to have influenced the submitted work.

Provenance and peer review: Not commissioned; externally peer reviewed.

Jahiel RI, Babor TF. Industrial epidemics, public health advocacy and the alcohol industry: lessons from other fields. Addiction 2007;102:1335-9. 


\section{Box 2: Leading business thinker Michael Porter presents his new world vision in the Harvard Business Review22}

"It is not philanthropy but self-interested behaviour to create economic value by creating societal value. If all companies individually pursued shared value connected to their particular businesses, society's overall interests would be served. And companies would acquire legitimacy in the eyes of the communities in which they operated, which would allow democracy to work as governments set policies that fostered and supported business."

The implications of this view for our way of life are profound. For example, Porter emphasises that his new world will certainly not involve any equalising of current wealth: "Nor is it about 'sharing' the value already created by firms-a redistribution approach. Instead, it is about expanding the total pool of economic and social value." This is a massive political statement which raises questions about relative rather than absolute poverty, the current inequities in society (ironically thrown into relief by corporate pay) and the sustainability of perpetual growth.

\section{Challenges for public health}

- Marketing by multinational corporations presents a major threat to public health; children are especially vulnerable

- As well as lifestyle illnesses such as lung cancer and liver cirrhosis, marketing threatens our mental wellbeing, exacerbates inequalities, and encourages unsustainable consumption

- Public health should take a lead in addressing these issues, revitalise its upstream, political functions, and regain its role as a champion of the underprivileged

- Public health should also be leading a quest for an economic system that actively promotes better public health

2 Lovato C, Linn G. Stead LF, Best A. Impact of tobacco advertising and promotion on increasing adolescent smoking behaviours. Cochrane Database Syst Rev 2003;4:CD003439

3 Anderson P, de Bruijn A, Angus K, Gordon R, Hastings G. Impact of alcohol advertising and media exposure on adolescent alcohol use: a systematic review of longitudinal studies. Alcohol Alcoholism 2009:44:229-43.

4 Cairns G, Angus K, Hastings G. The extent, nature and effects of food promotion to children: a review of the evidence to December 2008. WHO, 2009.

5 Bakan J. The corporation: the pathological pursuit of profit and power. Penguin, 2004 Foxall G, Goldsmith RE. Consumer psychology for marketers. Routledge, 1994.

7 Wensley R. The basics of marketing strategy. In Baker MJ, ed. The marketing book. 5th ed. Butterworth-Heinemann, 2003:53.

8 Grant IC, Hassan L, Hastings G, MacKintosh AM, Eadie D. The influence of branding on adolescent smoking behaviour: exploring the mediating role of image and attitudes. Int $J$ Nonprofit Voluntary Sector Marketing 2008;13:275-85

9 Hastings G, Brooks O, Stead M, Angus K, Anker T, Farrell T. Alcohol advertising: the las chance saloon. BMJ 2010;340: b5650.

10 Robinson TN, Borzekowski DL, Matheson DM, Kraemer HC. Effects of fast food branding on young children's taste preferences. Arch Pediatr Adolesc Med 2007;161:792-7.

11 House of Commons Health Committee. The influence of the pharmaceutical industry. Fourth report of session 2004-05. www.publications.parliament.uk/pa/cm200405/cmselect/ cmhealth/42/42.pdf.

12 University of Stirling. Dealing in drugs: an analysis of the pharmaceutical industry's marketing documents. House of Commons Health Select Committee written evidence
(Appendix 33, PI 125). www.publications.parliament.uk/pa/cm200405/cmselect/cmhealth/ 42/42we39.htm.

13 Wilkinson R, Pickett K. The spirit level: why equality is better for everyone. Penguin, 2010

14 Bradshaw T. Facebook strikes Diageo advertising deal. Financial Times 2011 Sep 18. www.ft.com/cms/s/2/d044ea24-e203-11e0-9915-00144feabdc0.html\#axzz22TFKW3zn.

15 Walker G. The bright side. Convenience Store 2012 Jun 8:53-64.

16 Collingwood Learning. Case studies. Smashed: a responsible drinking education programme. www.collingwoodlearning.com/diageoCS.php.

17 Hill L, Bakke O. Global alcohol corporations: what they tell us about themselves and why it's a worry. GAPA SHORE Meeting of Asia-Pacific NGOs on alcohol policies, Auckland 9-11 December 2005. http://apapaonline.org/APAPAnetwork/Meeting Reports/files/GAPA Auckland Dec05/GAPA Global Industry Dec05 Hill.pdf.

18 Framework Convention on Tobacco Control. The treaty. www.fctc.org/index.php?ltemid=5\& id $=8 \&$ option=com_content\&view=article.

9 Marmot M. Social determinants of health inequalities. Lancet 2005;365:1099.

20 Rayner G, Lang T. Ecological public health. Routledge, 2012.

21 Richter J. WHO reform and public interest safeguards: an historical perspective. Soc Med 2012;6:141-50..

22 Porter ME, Kramer MR. Creating shared value. Harvard Business Review 2011 Jan. http: //hbr.org/2011/01/the-big-idea-creating-shared-value./

Cite this as: BMJ 2012;345:e5124

@ BMJ Publishing Group Ltd 2012 


\section{Figure}

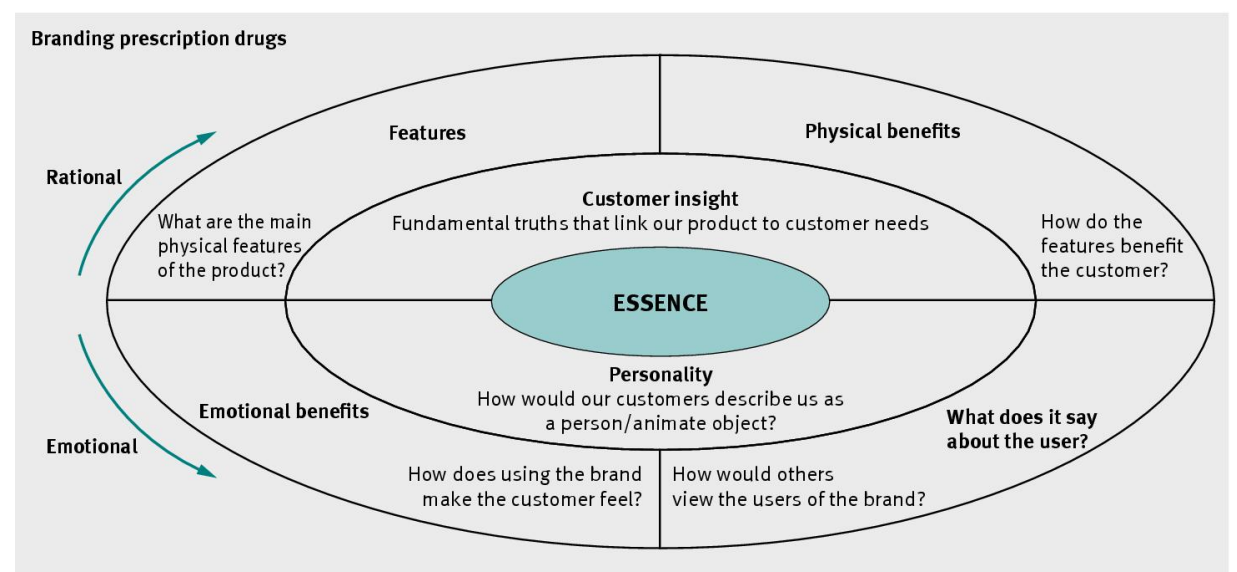

Branding prescription drugs: the diagram, which is from internal pharmaceutical industry documents, shows equal importance being attached to the role of rational and emotional dimensions in the development of strong brands ${ }^{12}$ 